\title{
Relative contribution of effects included in contemporary groups for adjusted and actual 120-day and 210-day weights in Nelore cattle in Brazil
}

Lillian Pascoa ${ }^{1}$, Arcadio de los Reyes ${ }^{2}$, Mauricio A. Elzo ${ }^{3}$, Jorge L. Ferreira ${ }^{4}$, Luiz A.F. Bezerra ${ }^{5}$ and Raysildo B. Lôbo ${ }^{5}$

${ }^{1}$ Instituto Federal de Educação, Ciência e Tecnologia de Brasília, Campus Planaltina, Planaltina, DF, Brazil.

${ }^{2}$ Departamento de Produção Animal, Escola de Veterinária, Universidade Federal de Goiás, Goiânia, GO, Brazil.

${ }^{3}$ Department of Animal Sciences, University of Florida, Gainesville, FL, USA.

${ }^{4}$ Universidade Federal do Tocantins, Araguaina, TO, Brazil.

${ }^{5}$ Departamento de Genética, Faculdade de Medicina de Ribeirão Preto, Universidade de São Paulo, Ribeirão Preto, SP, Brazil.

\begin{abstract}
The objective of this research was to estimate the relative magnitude of effects included in contemporary groups (CG) and their interactions with adjusted and actual $120 \mathrm{~d}$ and $210 \mathrm{~d}$ weights in 72,731 male and female Nelore calves born from 1985 to 2005 in 40 herds from PMGRN (Genetic Improvement Program of Nelore). Ten models with different $C G$ structures were compared. The analyses were done using the general linear models (GLM) procedure run in SAS software. All of the effects included in the $C G$ for each model were significant $(p<0.001)$ for the four traits analyzed. Inclusion of semester or trimester of birth as part of a CG was more appropriate than its use as an independent effect in the model because it accounted for interactions with the other effects in the CG. Calf sex (CS) and dam age at calving (DAC) had similar effects across the models, which suggested independence from other effects in these models. The corresponding age deviation effect had a larger impact on actual weight at $120 \mathrm{~d}$ than any other effect in all of the models tested. The use of actual weights in models with no CS effect in CG provides an alternative that would allow better genetic connectedness among CGs and greater accuracy in genetic evaluations.
\end{abstract}

Key words: beef cattle, models, preweaning growth.

Received: April 23, 2010; Accepted: June 15, 2011.

\section{Introduction}

Contemporary groups (CGs) are used in genetic evaluations to eliminate bias caused by systematic environmental effects such as differences in management, feeding and seasons (Van Vleck, 1987; Van Bebber et al., 1997; Carabaño et al., 2004; Cantet et al., 2005). However, a large number of CG can result in a small number of records per subclass, resulting in an increase in the variance of prediction errors and a reduction in the accuracy of genetic evaluations (Van Vleck, 1987; Van Bebber et al., 1997).

The length of time to identify animals belonging to the same CG within a herd is controversial. A balance between maximum accuracy and reduced bias must be achieved to optimize the definition of CG. The problem

Send correspondence to Lillian Pascoa. Instituto Federal de Educação, Ciência e Tecnologia de Brasília, Campus Planaltina, Rodovia DF 128, km 21, Zona Rural, 73380-900 Planaltina, DF, Brazil. E-mail: Ipascoa@hotmail.com. with the usual definition of $\mathrm{CG}$ is its arbitrary definition of periods of time that do not correspond to criteria for maximum accuracy and minimum bias (Schmitz et al., 1991; Carabaño et al., 2004). In an attempt to resolve this problem several criteria to compare different definitions of $C G$ that consider the estimated intra- $\mathrm{CG}$ variance, residual variance and accuracy of genetic evaluations have been proposed (Schmitz et al., 1991; Sivarajasingam, 1993; Van Bebber et al., 1997; Carabaño et al., 2004).

Brazil is known for its environmental diversity, with strong seasonal effects and fluctuations in pasture production that should be considered in the construction of CGs for genetic evaluation models (Fries and Ferraz, 2006). A significant influence in non-genetic effects and their interactions on growth in beef cattle has been widely proven in Brazil (Cardellino and Cardellino, 1984; Pons et al., 1989; Mascioli et al., 1996; Reyes et al., 1998, 2006; Paz et al., 1999; Cardoso et al., 2001; Bocchi et al., 2004). 
Several studies have shown that a linear adjustment of weight to a constant age at weaning in beef cattle does not completely remove the effect of age (Rossi et al., 1992; Villalba et al., 2000; Lobo and Martins Filho, 2002; Teixeira and Albuquerque, 2003; Reyes et al., 2004; Torres Júnior and Toral, 2006) because the age of the animal at weighing time influences its average daily gain and consequently its adjusted weight (Toral et al., 2007).

A model for genetic analysis should be preceded by careful study of systematic environmental effects and their interactions. The objective of this study was therefore to estimate and compare the relative magnitudes of effects included in CGs and their interactions on adjusted and actual calf weights at $120 \mathrm{~d}$ and $210 \mathrm{~d}$ of age in Nelore cattle in Brazil.

\section{Material and Methods}

The dataset consisted of adjusted and actual (real) weights at $120 \mathrm{~d}$ (AW120, RW120) and $210 \mathrm{~d}$ (AW210, RW210) of age from 72,731 male and female Nelore calves born from 1985 to 2005 in 40 herds belonging to PMGRN (Genetic Improvement Program of Nelore). Actual weights were those within $120 \pm 60 \mathrm{~d}$ of age for RW120 and within $210 \pm 60 \mathrm{~d}$ of age for RW210, and the corresponding ages were expressed as deviations (CAD - corresponding age deviations) for $120 \mathrm{~d}$ and $210 \mathrm{~d}$, respectively. Standardized weights were obtained by interpolation using a weight before and another after the standard age (120 d or $210 \mathrm{~d})$, with a maximum interval of $195 \mathrm{~d}$ between them $( \pm 90 \mathrm{~d}$ with a tolerance of 15 days because of possible changes in management). If there was no previous weight for AW120, then birth (either measured or the average of the breed: males $=33 \mathrm{~kg}$ and females $=31 \mathrm{~kg}$ ) was used as the first weight for the interpolation. Computations were done in a manner similar to that used by PMGRN (Lôbo, 1996):

$$
\mathrm{AW}=\mathrm{W}+[(\mathrm{W}-\mathrm{Wp}) / \mathrm{I}] \times(\mathrm{A}-\mathrm{Aw})
$$

where $\mathrm{AW}=$ adjusted weight at a standardized age (AW120 or AW210), W = nearest actual weight to a standardized age, $\mathrm{Wp}=$ previous weight, $\mathrm{I}=$ days between $\mathrm{W}$ and $\mathrm{Wp}, \mathrm{A}=$ standardized age $(120 \mathrm{~d}$ or $210 \mathrm{~d})$ and $\mathrm{Aw}=$ age at measurement of $\mathrm{W}$.

The effect of dam age at calving (DAC) was classified into six classes: $1=2 \mathrm{yr}, 2=3 \mathrm{yr}, 3=4 \mathrm{yr}, 4=5 \mathrm{yr}, 5=$ $6-9$ yr and $6=\geq 10$ yr old. Five CG structures, with a minimum of five records per subclass, were defined as follows:

$\mathrm{CG}_{1}$ : herd - year of birth - management group at each age.

$\mathrm{CG}_{2}: \mathrm{CG}_{1}$ - semester of birth.

$\mathrm{CG}_{3}: \mathrm{CG}_{1}$ - trimester of birth.

$\mathrm{CG}_{4}: \mathrm{CG}_{2}$ - calf sex.

$\mathrm{CG}_{5}: \mathrm{CG}_{3}$ - calf sex.

The GLM procedure of SAS was used to estimate the relative importance of effects included in CGs and their in- teractions in 10 linear models. The structure of these models (M) was as follows:

$$
\begin{aligned}
& \mathrm{M}_{1}: \text { Weight }=\alpha+\mathrm{CG}_{1}+\mathrm{SB}+\mathrm{CS}+\mathrm{DAC}+\varepsilon \\
& \mathrm{M}_{1 \mathrm{~A}}: \text { Weight }=\alpha+\mathrm{CG}_{1}+\mathrm{TB}+\mathrm{CS}+\mathrm{DAC}+\varepsilon \\
& \mathrm{M}_{1 \mathrm{~B}}: \text { Weight }=\alpha+\mathrm{CG}_{1}+\mathrm{CS}+\mathrm{DAC}+\mathrm{JDB}+\varepsilon \\
& \mathrm{M}_{1 \mathrm{C}}: \text { Weight }=\alpha+\mathrm{CG}_{1}+\mathrm{CS}+\mathrm{DAC}+\mathrm{JDB}(\mathrm{CS})+\varepsilon \\
& \mathrm{M}_{2}: \text { Weight }=\alpha+\mathrm{CG}_{2}+\mathrm{CS}+\mathrm{DAC}+\varepsilon \\
& \mathrm{M}_{3}: \text { Weight }=\alpha+\mathrm{CG}_{3}+\mathrm{CS}+\mathrm{DAC}+\varepsilon \\
& \mathrm{M}_{3 \mathrm{~A}}: \text { Weight }=\alpha+\mathrm{CG}_{3}+\mathrm{CS}+\mathrm{DAC}(\mathrm{CS})+\varepsilon \\
& \mathrm{M}_{3 \mathrm{~B}}: \text { Weight }=\alpha+\mathrm{CG}_{3}+\mathrm{CS}+\mathrm{DAC}+\mathrm{CAD}(\mathrm{CS})+\varepsilon \\
& \mathrm{M}_{4}: \text { Weight }=\alpha+\mathrm{CG}_{4}+\mathrm{DAC}+\varepsilon \\
& \mathrm{M}_{5}: \text { Weight }=\alpha+\mathrm{CG}_{5}+\mathrm{DAC}+\varepsilon
\end{aligned}
$$

where Weight $=$ adjusted or actual weight at $120 \mathrm{~d}$ or $210 \mathrm{~d}$ of age, $\alpha=$ a constant, $\mathrm{CG}=$ contemporary group, $\mathrm{SB}=$ semester of calf birth, TB = trimester of calf birth, $\mathrm{CS}=$ calf sex, DAC = class of dam age at calving (one of the six classes defined above), JDB = Julian date of calf birth, $\mathrm{CAD}=$ calf age deviation (deviation from $120 \mathrm{~d}$ or $210 \mathrm{~d}$ ) and $\varepsilon=$ a residual. The CAD effect was modeled as a cubic polynomial in all analyses using actual weights (RW120 and RW210).

The adjustability of the models was evaluated using an adjusted coefficient of determination $\left(\mathrm{R}_{\mathrm{A}}^{2}=1\right.$ - [residual mean square / total mean square]) and an estimate of the residual variance. The contribution of each effect to the $\mathrm{R}^{2}$ coefficient for each model was computed as the ratio of the sum of squares due to each effect (Type I) and the total sum of squares.

Models for adjusted weights (AW120 and AW210) were defined as follows. Models $\mathrm{M}_{1}$ to $\mathrm{M}_{1 \mathrm{C}}$ included the effects of $\mathrm{CG}_{1}$, calf sex (CS), dam age at calving (DAC), and season of birth defined as semester of birth $\left(\mathrm{SB}, \mathrm{M}_{1}\right)$, trimester of birth (TB, $\mathrm{M}_{1 \mathrm{~A}}$ ) and Julian date of calf birth (cubic polynomial; JDB, $\mathrm{M}_{1 \mathrm{~B}}$ ), and Julian date of calf birth date nested within calf sex (cubic polynomial; JDB(CS), $\mathrm{M}_{1 \mathrm{C}}$ ). Model $\mathrm{M}_{2}$ included $\mathrm{CG}_{2}=\mathrm{CG}_{1}-\mathrm{SB}$, whereas models $\mathrm{M}_{3}$ and $\mathrm{M}_{3 \mathrm{~A}}$ contained $\mathrm{CG}_{3}=\mathrm{CG}_{1}-\mathrm{TB}$, and these three models included the effects of CS and DAC; DAC was nested within $\mathrm{CS}$ in $\mathrm{M}_{3 \mathrm{~A}}$. Model $\mathrm{M}_{4}$ tested $\mathrm{CG}_{4}=\mathrm{CG}_{2}-\mathrm{CS}$, model $\mathrm{M}_{5}$ had $\mathrm{CG}_{5}=\mathrm{CG}_{3}-\mathrm{CS}$, and both models included DAC. Models for actual weights (RW120 and RW210) contained the same effects as models for adjusted weights plus the effect of calf age at weight expressed as a deviation from $120 \mathrm{~d}$ or $210 \mathrm{~d}$ of age (CAD) as a cubic polynomial. This model was tested using $\mathrm{M}_{3 \mathrm{~B}}$, where a cubic polynomial CAD effect was nested within CS.

\section{Results and Discussion}

Table 1 shows descriptive statistics for adjusted and actual weights at $120 \mathrm{~d}$ and $210 \mathrm{~d}$ of age. Larger ranges and greater standard deviations were observed for actual weights compared to standardized weights at both ages because of the effect of calf age on weight measurements. 
Table 1 - Number of observations and mean, minimum, maximum and standard deviations of adjusted weights (AW) and actual weights (RW) in Nelore cattle at $120 \mathrm{~d}$ and $210 \mathrm{~d}$ of age.

\begin{tabular}{lccccc}
\hline Trait & $\mathrm{N}$ & Mean $(\mathrm{kg})$ & Min $(\mathrm{kg})$ & Max $(\mathrm{kg})$ & $\mathrm{Std}(\mathrm{kg})$ \\
\hline AW120 & 70,543 & 124.8 & 54 & 218 & 18.9 \\
RW120 & 70,677 & 128.3 & 34 & 276 & 29.5 \\
AW210 & 65,607 & 181.2 & 73 & 307 & 27.7 \\
RW210 & 69,978 & 182.7 & 57 & 327 & 32.9 \\
\hline
\end{tabular}

Max $=$ maximum, Min $=$ minimum, $\mathrm{N}=$ number of observations, Std $=$ standard deviation

Table 2 shows the number of CGs and the mean number of records per $\mathrm{CG}$ for the five $\mathrm{CG}$ structures defined here. For weight at $120 \mathrm{~d}$ the number of subclasses remained constant between the actual and standardized weights and the average size of the five CG structures was similar. On the other hand, for weight at $210 \mathrm{~d}, \mathrm{CG}$ number and size were slightly larger for actual weights than for standardized weights in all five CG structures, possibly because of management conditions in the herds where the animals were located. A large proportion of animals was weighed before the standard age of $210 \mathrm{~d}$ and subsequently at ages beyond the maximum interval of $195 \mathrm{~d}$ (maximum interval allowed for standardization), thus explaining the difference between the actual weights and weights standardized to $210 \mathrm{~d}$.

The relative contributions of each effect to the coefficient of determination $\left(\mathrm{R}^{2}\right)$ in each model are summarized in Table 3. All effects were significant $(p<0.001)$ for the four traits analyzed (AW120, AW210, RW120 and RW210).

The smallest contribution of seasonal effects was for SB $\left(M_{1}\right)$, the largest was for JDB $\left(M_{1 B}\right)$, and the effect of TB $\left(\mathrm{M}_{1 \mathrm{~A}}\right)$ was intermediate between $\mathrm{SB}\left(\mathrm{M}_{1}\right)$ and JDB $\left(\mathrm{M}_{1 \mathrm{~B}}\right)$. Maximum $\mathrm{R}_{\mathrm{A}}{ }(\%)$ differences for AW120, AW210, RW120 and RW210 were between those for $M_{1 B}$ and $M_{1}$ $(0.4,3.2,0.2$ and 2.5 , respectively), and the corresponding maximum reductions in $\mathrm{V}_{\mathrm{R}}(\%)$ were $0.6,5.4,0.5$ and 5.2. These results clearly indicate that seasonal effects were more important for weight at $210 \mathrm{~d}$ of age than at $120 \mathrm{~d}$ of age, in agreement with the findings of Reyes et al. (1998) for adjusted weights at $120 \mathrm{~d}$ and $240 \mathrm{~d}$ of age in Nelore cattle.

The differences in $\mathrm{R}_{\mathrm{A}}^{2}(\%)$ between models $\mathrm{M}_{5}$ and $\mathrm{M}_{1}$ showed increases of 3.2, 5.03, 1.5 and 3.9, accompanied by reductions in $\mathrm{V}_{\mathrm{R}}(\%)$ of 5.0, 8.9, 4.9 and 8.0 for AW120, AW210, RW120 and RW210, respectively. The differences in $\mathrm{R}_{\mathrm{A}}^{2}(\%)$ between models $\mathrm{M}_{2}$ and $\mathrm{M}_{1}(1.4,1.7,0.6$ and 1.3 for AW120, AW210, RW120 and RW210, respectively) reflected the contribution of interactions between $\mathrm{SB}$ and the other effects in CG. The contribution of interactions between TB and the rest of the effects contained in $\mathrm{CG}_{3}$ were 2.5, 2.7, 1.2, and 2.1 for the same four traits $\left(\mathrm{M}_{3}\right.$ $\left.\mathrm{M}_{1 \mathrm{~A}}\right)$. These values showed that interactions involving $\mathrm{SB}$
Table 2 - Number of contemporary groups $\left(1^{\text {st }}\right.$ line) and mean number of animals per contemporary group ( $2^{\text {nd }}$ line) for adjusted weights (AW) and actual weights (RW) in Nelore cattle at $120 \mathrm{~d}$ and $210 \mathrm{~d}$ of age.

\begin{tabular}{lccccc}
\hline Trait & $\mathrm{CG}_{1}$ & $\mathrm{CG}_{2}$ & $\mathrm{CG}_{3}$ & $\mathrm{CG}_{4}$ & $\mathrm{CG}_{5}$ \\
\hline AW120 & 456 & 688 & 1,077 & 1,093 & 1,670 \\
& 154.7 & 102.5 & 65.5 & 64.5 & 42.2 \\
\hline RW120 & 456 & 688 & 1,077 & 1,093 & 1,670 \\
& 155.0 & 102.7 & 65.6 & 64.7 & 42.3 \\
\hline AW210 & 459 & 674 & 1,042 & 1,057 & 1,609 \\
& 142.9 & 97.3 & 63.0 & 62.1 & 40.8 \\
\hline RW210 & 472 & 699 & 1,081 & 1,098 & 1,667 \\
& 148.3 & 100.1 & 64.7 & 63.7 & 42.0 \\
\hline
\end{tabular}

$\mathrm{CG}_{1}$ : herd - year of birth - management group at each age; $\mathrm{CG}_{2}: \mathrm{CG}_{1}$ - semester of birth; $\mathrm{CG}_{3}: \mathrm{CG}_{1}$ - trimester of birth; $\mathrm{CG}_{4}: \mathrm{CG}_{2}$ - calf sex; $\mathrm{CG}_{5}$ : $\mathrm{CG}_{3}$ - calf sex.

$\left(\mathrm{M}_{1}\right)$ and TB $\left(\mathrm{M}_{1 \mathrm{~A}}\right)$ were of similar importance and that inclusion of some seasonal class effects within a CG would be more effective than their inclusion as an independent main effect (including as JDB) or the application of a correction factor for these effects. Similar results were found by Reyes et al. (1998) for adjusted weights at $120 \mathrm{~d}$ and $240 \mathrm{~d}$ of age in Nelore cattle, and by Reyes et al. (2006) for preweaning growth in a multibreed Nelore $\mathrm{x}$ Hereford population.

As shown in Table $2, \mathrm{CG}_{2}$ had only $62.9 \%$ of $\mathrm{CG}$, but a mean $\mathrm{CG}$ size $58.9 \%$ larger than $\mathrm{CG}_{4}$ for $\mathrm{AW} 120$; the corresponding values for AW210, RW120 and RW210 were $63.8 \%$ and $56.7 \%, 62.9 \%$ and $58.7 \%$, and $63.7 \%$ and $57.1 \%$, respectively. Table 2 also shows that $\mathrm{GC}_{3}$ had $64.5 \%$ of $\mathrm{CG}$ and a mean CG size $55.2 \%$ larger than $\mathrm{GC}_{5}$ for AW120; the corresponding values for AW210, RW120 and RW210 were $64.8 \%$ and $54.4 \%, 64.5 \%$ and $55.1 \%$, and $64.8 \%$ and $54.0 \%$, respectively. Significant differences among the CG structures were accompanied by increases in $\mathrm{R}_{\mathrm{A}}^{2}(\%)$ between 0.26 (RW120) and 0.84 (AW210), and reductions in $\mathrm{V}_{\mathrm{R}}(\%)$ between 0.83 (RW120) and 1.46 (AW210). These results identified models $\mathrm{M}_{2}\left(\mathrm{GC}_{2}\right.$ with $\mathrm{SB})$ and $\mathrm{M}_{3}\left(\mathrm{GC}_{3}\right.$ with $\left.\mathrm{TB}\right)$, both without $\mathrm{CS}$ in their $\mathrm{CG}$ but with $\mathrm{R}_{\mathrm{A}}^{2}$ (\%) differences between 0.61 (RW120) and 1.98 (RW210), as viable alternatives for use in genetic evaluations of preweaning growth traits.

Estimates of the effects of CS and DAC and their contributions to $\mathrm{R}^{2}$ were similar for all traits in all models. The estimates for CS(\%) were 3.9, 4.7, 1.8 and 3.3 for AW120, AW210, RW120 and RW210, respectively, and for DAC (\%) they were 4.1, 1.9, 1.7 and 1.6, respectively. Similar estimates for CS and DAC were obtained for preweaning growth in Nelore $\mathrm{x}$ Hereford crosses (Reyes et al., 2006). These results indicated that CS and DAC were independent of the other effects in the models considered here for all four traits, and that, for both adjusted and actual weights, CS was more important than DAC at $210 \mathrm{~d}$ of age, 
whereas the opposite was true at $120 \mathrm{~d}$ of age. These results agreed with the expectation of an increase in the importance of the sex effect and a decrease in maternal influence as the animals grow older; they also support the current practice of including maternal effects when evaluating growth in young calves.

Table 3 - Relative contribution of each effect to fitting of the models, expressed as a fraction of the coefficient of determination $\left(\mathrm{R}^{2}\right)$ for adjusted weights (AW120 and AW210) and actual weights (RW120 and RW210) in Nelore cattle at $120 \mathrm{~d}$ and $210 \mathrm{~d}$ of age.

\begin{tabular}{|c|c|c|c|c|c|c|c|c|c|c|}
\hline Model terms $^{\mathrm{a}}$ & $\mathrm{M}_{1}$ & $\mathrm{M}_{1 \mathrm{~A}}$ & $\mathrm{M}_{1 \mathrm{~B}}$ & $\mathrm{M}_{\mathrm{lC}}$ & $\mathrm{M}_{2}$ & $\mathrm{M}_{3}$ & $\mathrm{M}_{3 \mathrm{~A}}$ & $\mathrm{M}_{3 \mathrm{~B}}$ & $\mathrm{M}_{4}$ & $\mathrm{M}_{5}$ \\
\hline \multicolumn{11}{|c|}{ Adjusted weight (AW120-1 $1^{\text {st. }}$ row) and actual weight (RW120- $2^{\text {nd. }}$ row) at 120 days of age } \\
\hline \multirow[t]{2}{*}{$\mathrm{CG}$} & 0.2848 & 0.2848 & 0.2848 & 0.2848 & 0.3163 & 0.3320 & 0.3320 & - & 0.3659 & 0.3832 \\
\hline & 0.1753 & 0.1753 & 0.1753 & 0.1753 & 0.2052 & 0.2520 & 0.2520 & 0.2520 & 0.2326 & 0.2805 \\
\hline \multirow[t]{2}{*}{ SB } & 0.0139 & 0.0149 & - & - & - & - & - & - & - & - \\
\hline & 0.0098 & 0.0101 & - & - & - & - & - & - & - & - \\
\hline \multirow[t]{2}{*}{$\mathrm{CS}$} & 0.0390 & 0.0389 & 0.0394 & 0.0394 & 0.0387 & 0.0383 & 0.0383 & - & - & - \\
\hline & 0.0181 & 0.0181 & 0.0183 & 0.0183 & 0.0179 & 0.0176 & 0.0176 & 0.0176 & - & - \\
\hline \multirow[t]{2}{*}{ CAD } & - & - & - & - & - & - & - & - & - & - \\
\hline & 0.4680 & 0.4676 & 0.4617 & 0.4613 & 0.4555 & 0.4172 & 0.4173 & ${ }^{\mathrm{c}} 0.4186$ & 0.4311 & 0.4125 \\
\hline \multirow[t]{2}{*}{ DAC } & 0.0421 & 0.0421 & 0.0411 & 0.0411 & 0.0406 & 0.0406 & ${ }^{\mathrm{c}} 0.0410$ & - & 0.0386 & 0.0383 \\
\hline & 0.0178 & 0.0183 & 0.0172 & 0.0172 & 0.0178 & 0.0173 & ${ }^{\mathrm{c}} 0.0174$ & 0.0173 & 0.0169 & 0.0163 \\
\hline \multirow[t]{2}{*}{ JDB } & - & - & 0.0181 & ${ }^{\mathrm{c}} 0.0184$ & - & - & - & - & - & - \\
\hline & - & - & 0.0180 & ${ }^{\mathrm{c}} 0.0185$ & - & - & - & - & - & - \\
\hline \multirow[t]{2}{*}{$V_{R}^{b}$} & 223.62 & 223.29 & 222.33 & 222.26 & 218.64 & 214.31 & 214.16 & - & 216.67 & 212.25 \\
\hline & 273.06 & 272.65 & 271.68 & 271.57 & 267.43 & 262.15 & 261.99 & 260.96 & 265.20 & 259.73 \\
\hline \multirow[t]{2}{*}{$\mathrm{R}^{2 \mathrm{~b}}$} & 0.3798 & 0.3807 & 0.3834 & 0.3836 & 0.3956 & 0.4109 & 0.4113 & - & 0.4045 & 0.4215 \\
\hline & 0.6889 & 0.6894 & 0.6905 & 0.6907 & 0.6964 & 0.7040 & 0.7042 & 0.7054 & 0.7006 & 0.7092 \\
\hline \multirow[t]{2}{*}{$\mathrm{R}_{\mathrm{A}}^{2} \mathrm{~b}$} & 0.3757 & 0.3766 & 0.3793 & 0.3795 & 0.3896 & 0.4017 & 0.4021 & - & 0.3951 & 0.4075 \\
\hline & 0.6869 & 0.6874 & 0.6885 & 0.6886 & 0.6933 & 0.6994 & 0.6996 & 0.7008 & 0.6959 & 0.7022 \\
\hline \multicolumn{11}{|c|}{ Adjusted weight (AW210-1 $1^{\text {st }}$ row) and actual weight (RW210-2 ${ }^{\text {nd }}$ row) at 210 days of age } \\
\hline \multirow[t]{2}{*}{ CG } & 0.3212 & 0.3212 & 0.3212 & 0.3212 & 0.3668 & 0.3926 & 0.3926 & - & 0.4259 & 0.4541 \\
\hline & 0.2553 & 0.2553 & 0.2553 & 0.2553 & 0.3038 & 0.3358 & 0.3358 & 0.3358 & 0.3479 & 0.3821 \\
\hline \multirow[t]{2}{*}{ SB } & 0.0264 & 0.0391 & - & - & - & - & - & - & - & - \\
\hline & 0.0276 & 0.0348 & - & - & - & - & - & - & - & - \\
\hline \multirow[t]{2}{*}{$\mathrm{CS}$} & 0.0469 & 0.0480 & 0.0478 & 0.0478 & 0.0463 & 0.0471 & 0.0471 & - & - & - \\
\hline & 0.0326 & 0.0334 & 0.0333 & 0.0333 & 0.0326 & 0.0333 & 0.0333 & 0.0333 & - & - \\
\hline \multirow[t]{2}{*}{ CAD } & - & - & - & - & - & - & - & - & - & - \\
\hline & 0.1874 & 0.1882 & 0.1895 & 0.1890 & 0.1807 & 0.1677 & 0.1678 & ${ }^{\mathrm{c}} 0.1685$ & 0.1792 & 0.1658 \\
\hline \multirow[t]{2}{*}{ DAC } & 0.0174 & 0.0211 & 0.0168 & 0.0168 & 0.0171 & 0.0212 & ${ }^{\mathrm{c}} 0.0213$ & - & 0.0160 & 0.0197 \\
\hline & 0.0152 & 0.0176 & 0.0145 & 0.0145 & 0.0153 & 0.0177 & ${ }^{\mathrm{c}} 0.0178$ & 0.0177 & 0.0142 & 0.0164 \\
\hline \multirow[t]{2}{*}{ JDB } & - & - & 0.0579 & ${ }^{\mathrm{c}} 0.0581$ & - & - & - & - & - & - \\
\hline & - & - & 0.0506 & ${ }^{\mathrm{c}} 0.0513$ & - & - & - & - & - & - \\
\hline \multirow[t]{2}{*}{$V_{R}^{b}$} & 454.99 & 441.56 & 430.43 & 430.25 & 442.29 & 420.93 & 420.83 & - & 435.84 & 414.41 \\
\hline & 525.15 & 513.15 & 498.06 & 497.84 & 511.47 & 489.99 & 489.88 & 489.17 & 504.61 & 483.19 \\
\hline \multirow[t]{2}{*}{$\mathrm{R}^{2 \mathrm{~b}}$} & 0.4120 & 0.4293 & 0.4437 & 0.4440 & 0.4303 & 0.4608 & 0.4610 & - & 0.4419 & 0.4738 \\
\hline & 0.5183 & 0.5293 & 0.5431 & 0.5433 & 0.5323 & 0.5544 & 0.5546 & 0.5552 & 0.5412 & 0.5643 \\
\hline \multirow[t]{2}{*}{$\mathrm{R}_{\mathrm{A}}^{2} \mathrm{~b}$} & 0.4078 & 0.4252 & 0.4397 & 0.4400 & 0.4243 & 0.4521 & 0.4522 & - & 0.4327 & 0.4606 \\
\hline & 0.5149 & 0.5260 & 0.5399 & 0.5401 & 0.5276 & 0.5474 & 0.5475 & 0.5482 & 0.5339 & 0.5537 \\
\hline
\end{tabular}

${ }^{a}$ For each term: Adjusted weights $\left(1^{\text {st. }}\right.$ row $)$ and actual weights $\left(2^{\text {nd. }}\right.$ row $) . C G=$ Contemporary group; $\left(\mathrm{CG}_{1} \mathrm{M}_{1}\right.$ to $\left.\mathrm{M}_{1 \mathrm{C}}\right)=$ concatenation of herd - year of birth - management groups at 120 and 210 days of age; $\left(\mathrm{CG}_{2} \mathrm{M}_{2}\right)=$ concatenation of $\mathrm{CG}_{1}$ - semester of birth; $\left(\mathrm{CG}_{3} \mathrm{M}_{3}\right.$ to $\left.\mathrm{M}_{3 \mathrm{~B}}\right)=$ concatenation of $C \mathrm{G}_{1}$ trimester of birth. $\mathrm{CS}=$ calf sex. $\left(\mathrm{CG}_{4} \mathrm{M}_{4}\right)=$ concatenation of $\mathrm{CG}_{2}-\mathrm{CS} ;\left(\mathrm{CG}_{5} \mathrm{M}_{5}\right)=$ concatenation of $\mathrm{CG}_{3}-\mathrm{CS}$. $\mathrm{SB}=$ season of birth, semester $\left(\mathrm{M}_{1}\right)$, trimester $\left(\mathrm{M}_{1 \mathrm{~A}}\right), \mathrm{JDB}=\mathrm{Julian}$ date of calf birth (1 to 366 days, $\left.\mathrm{M}_{1 \mathrm{~B}}\right)$; JDB(CS) $\mathrm{M}_{1 \mathrm{C}} ; \mathrm{CAD}=$ calf age at weighing as deviation from 120 or 210 days; $\mathrm{DAC}=$ dam age at calving class (one of six classes as defined in the text); $\mathrm{DAC}(\mathrm{CS}) \mathrm{M}_{3 \mathrm{~A}} ; \mathrm{CAD}(\mathrm{CS}) \mathrm{M}_{3 \mathrm{~B}}$.

${ }^{b} V_{R}=$ residual variance. $R^{2}=$ coefficient of determination of the model. $R_{A}^{2}=$ adjusted $R^{2}=1$ - (residual mean square / total mean square) ${ }^{c}$ Effects of DAC(CS) $\mathrm{M}_{3 \mathrm{~A}}$, and of cubic polynomial regressions of AW120 or AW210 on JDB(CS) $\mathrm{M}_{1 \mathrm{C}}$, and of RW120 or RW210 on CAD(CS) M $\mathrm{JDB}(\mathrm{CS}) \mathrm{M}_{1 \mathrm{C}}$. 
Differences of $0.6,0.8,0.3$, and 0.6 in $\mathrm{R}_{\mathrm{A}}^{2}(\%)$ between models $\mathrm{M}_{4}$ and $\mathrm{M}_{2}$ and reductions in $\mathrm{V}_{\mathrm{R}}(\%)$ of 0.9 , 1.5, 0.8 and 1.4, for AW120, AW210, RW120 and RW210, respectively, represented the contribution of interactions between CS and the remaining effects in $C_{2}$. Similarly, $\mathrm{R}_{\mathrm{A}}^{2}(\%)$ differences between models $\mathrm{M}_{5}$ and $\mathrm{M}_{3}$ and reductions in $\mathrm{V}_{\mathrm{R}}(\%)$ were attributable to the combined effect of interactions between $\mathrm{CS}$ and the other components of $\mathrm{CG}_{3}$. The corresponding values were $0.6,0.9,0.3$ and 0.6 for differences in $\mathrm{R}_{\mathrm{A}}^{2}(\%)$ and 1.0, 1.6, 0.9 and 1.4 for reductions in $V_{R}(\%)$ for AW120, AW210, RW120 and RW210, respectively. The low interaction between CS and other CG components in $\mathrm{CG}_{2}$ and $\mathrm{CG}_{3}$ relative to the main $\mathrm{CS}$ effect suggested that CS can be included as a class effect separately from $\mathrm{CG}$, and that this will have a very small impact on the adjustment of records. In addition, an independent CS effect will decrease the number of CGs and increase their size, thereby increasing connectedness and the accuracy of genetic evaluations. These results showed that estimates of CS were similar across models and reconfirmed the results for Nelore $x$ Hereford cattle (Reyes et al., 2006).

Although significant, within sex estimates of DAC $\left(\mathrm{M}_{3 \mathrm{~A}}\right)$ and JDB $\left(\mathrm{M}_{1 \mathrm{C}}\right)$ for all four traits, and of CAD $\left(\mathrm{M}_{3 \mathrm{~B}}\right)$ for actual weights did not show appreciable contributions to the increase in $\mathrm{R}_{\mathrm{A}}^{2}(<0.1 \%)$ or to the reduction in $\mathrm{V}_{\mathrm{R}}$ ( $<1$ unit), suggesting that these effects would not need to be included in the usual models for genetic evaluation of preweaning growth traits where simple models are required. Reyes et al. (2006) reached a similar conclusion for Nelore x Hereford cattle.

The contribution of the CAD effect was large relative to other effects in the CGs tested here. The CAD contributed most to the increase in $\mathrm{R}_{\mathrm{A}}^{2}$ and the reduction in $\mathrm{V}_{\mathrm{R}}$, and was one of the most important effects for weight at $210 \mathrm{~d}$. Figure 1 shows the cubic polynomial regressions of calf actual weights on days of age expressed as deviations from $120 \mathrm{~d}$ and $210 \mathrm{~d}$, estimated using models $\mathrm{M}_{2}, \mathrm{M}_{3}, \mathrm{M}_{4}$ and $\mathrm{M}_{5}$. The quadratic and cubic terms were significant $(\mathrm{p}<0.05)$ for both traits in all models, reconfirming that the relationship between weight and age is not linear, in agreement with previous findings (Rossi et al., 1992; Lobo and Martins Filho, 2002; Reyes et al., 2004; Torres Júnior and Toral, 2006). Hence, the use of actual weights measured within an interval centered on a pre-established standard age, and inclusion of the effect of calf age in the analysis model provides an advantageous alternative for genetic evaluations.
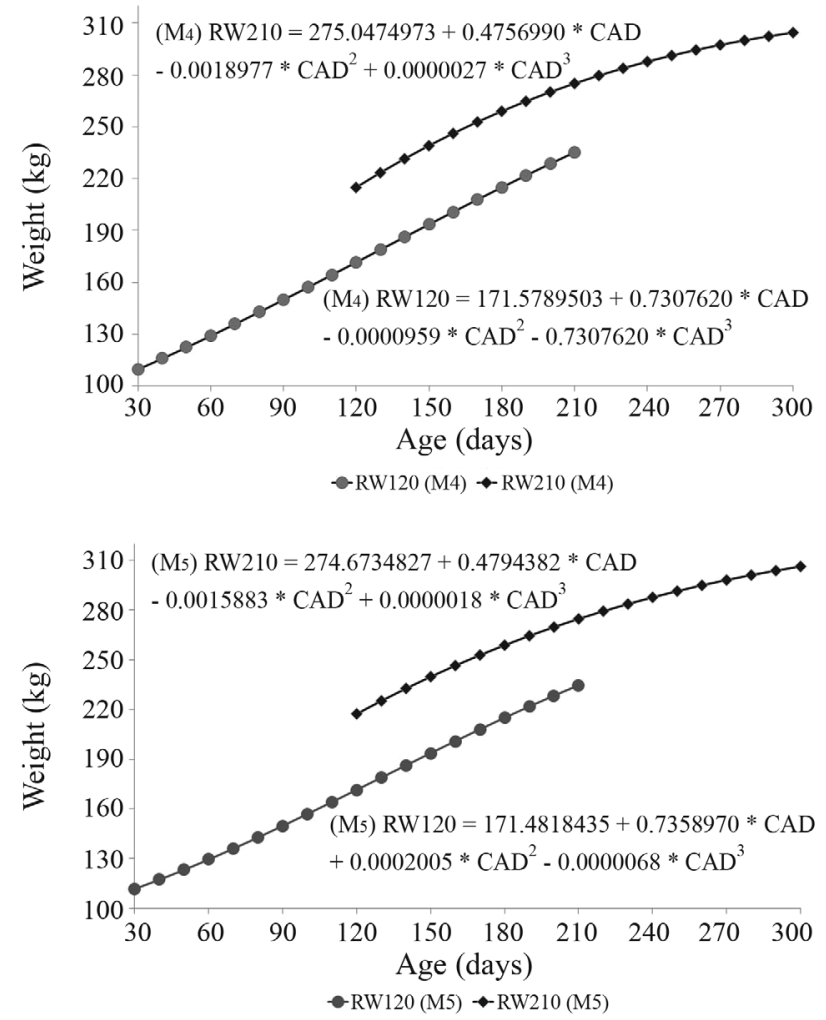

Figure 1 - Cubic polynomial regressions of actual weights at $120 \mathrm{~d}$ (RW120) and $210 \mathrm{~d}$ (RW210) on age expressed as deviations (CAD), estimated with models $\mathrm{M}_{2}, \mathrm{M}_{3}, \mathrm{M}_{4}$ and $\mathrm{M}_{5}$. RW120: actual weight at $120 \mathrm{~d} ; \mathrm{RW} 210$ : actual weight at $210 \mathrm{~d} ; \mathrm{CAD}=$ calf age at weighing as deviation from 120 or 210 days; $\mathrm{M}_{2}:$ weight $=\alpha+\mathrm{CG}_{2}+\mathrm{CS}+\mathrm{DAC}+\varepsilon ; \mathrm{M}_{3}:$ weight $=\alpha+\mathrm{CG}_{3}+\mathrm{CS}+\mathrm{DAC}+\varepsilon ; \mathrm{M}_{4}:$ weight $=\alpha+\mathrm{CG}_{4}+\mathrm{DAC}+\varepsilon ; \mathrm{M}_{5}:$ weight $=\alpha+\mathrm{CG}_{5}+\mathrm{DAC}+\varepsilon ;$ $\mathrm{CG}=$ contemporary group; $\left(\mathrm{CG}_{2} \mathrm{M}_{2}\right)=$ concatenation of herd - year of birth - management groups at 120 and 210 days of age - semester of birth; $\left(\mathrm{CG}_{3}\right.$ $\left.\mathrm{M}_{3}\right)=$ concatenation of herd - year of birth - management groups at 120 and 210 days of age - trimester of birth. $\left(\mathrm{CG}_{4} \mathrm{M}_{4}\right)=$ concatenation of $C \mathrm{G}_{2}-\mathrm{CS}$ $\left(\mathrm{CG}_{5} \mathrm{M}_{5}\right)=$ concatenation of $\mathrm{CG}_{3}-\mathrm{CS} . \mathrm{CS}=$ calf sex. $\mathrm{DAC}=$ dam age at calving class (one of six classes as defined in the text). 
In conclusion, the independence of calf sex effects from other effects in the CGs tested here suggests that this effect could be modeled separately from CG effects. This independence creates a promising alternative for modeling genetic analyses of preweaning growth traits that would increase the size of CGs and the accuracy of genetic predictions. The inclusion of semester or trimester of birth as part of a CG was more appropriate than independent estimates of these effects because it accounted for interactions with all other components of a CG. Estimates of Julian date of calf birth, dam age at calving, and calf age at weighing within calf sex suggested that genetic evaluation models for preweaning growth traits need not include these effects, which means that simpler models for these traits can be used. The use of actual weights in models that include a season of birth effect within CGs and model calf sex separately constitute alternatives that could improve genetic connectedness among CGs and help increase the accuracy of genetic evaluations.

\section{References}

Bocchi AL, Teixeira RA and Albuquerque LG (2004) Age of dam effect and month of birth effect on nelore's weaning weight in different brazilian regions. Acta Scient Anim Sci 26:475482.

Cantet RJC, Birchmeier AN, Canaza Cayo AW and Fioretti C (2005) Semiparametric animal models via penalized splines as alternatives to models with contemporary groups. J Anim Sci 83:2482-2494.

Carabaño MJ, Moreno A, López-Romero P and Díaz C (2004) Comparing alternative definitions of the contemporary group effect in Avileña Negra Ibérica beef cattle using classical and Bayesian criteria. J Anim Sci 82:3447-3457.

Cardellino MV and Cardellino RA (1984) Environmental factors on weight, weight gains and conformation at weaning of Hereford calves in Rio Grande do Sul - Brazil. Rev Bras Zootec 13:547-556.

Cardoso FF, Cardellino RA and Campos LT (2001) Environmental factors that affect the performance from birth to weaning of Angus calves raised in the state of Rio Grande do Sul Brazil. Rev Bras Zootec 30:1683-1688.

Fries LA and Ferraz JBS (2006) Beef cattle genetic programmes in Brazil. In: $8^{\text {th }}$ World Congress on Genetics Applied to Livestock Production, Belo Horizonte.

Lôbo RB (1996) Programa de Melhoramento Genético da Raça Nelore. 2nd edition. ANCP, Ribeirão Preto, 104 pp.

Lôbo RNB and Martins-Filho R (2002) Evaluation of body weight standardization methods for 205, 365 and 550 days of age. Rev Bras Zootec 31:1695-1706.

Mascioli AS, Alencar MM and Barbosa PF (1996) Influence of environmental factors on weights of Canchim cattle. Rev Bras Zootec 25:853-865.

Paz CCP, Albuquerque LG and Fries LA (1999) Environmental effects on weight Gain from the birth to weaning period in Nellore breed cattle. Rev Bras Zootec 28:55-64.

Pons SB, Milagres JC and Teixeira NM (1989) Effects of genetic and environmental factors on growth and conformation score in Hereford cattle in Rio Grande do Sul I. Weight and conformation score at weaning. Rev Bras Zootec 18:391401.

Reyes A, Faria CU, Dias DSO, Brito RAM and Barbosa V (2004) Viés na padronização linear de pesos a idades constantes em bovinos de corte. In: V Simpósio da Sociedade Brasileira de Melhoramento Animal, Pirassununga.

Reyes A, Lobo RB, Bezerra LAF and Martins EN (1998) Critérios de época na conformação de grupos contemporâneos para características de crescimento em Nelore. In: Anais $35^{\mathrm{a}}$ Reunião Anual de Sociedade Brasileira de Zootecnia, Botucatu, v. 3, pp 437-439.

Rossi DJ, Kress DD, Tess MWB and Burfening PJ (1992) Correcting bias from the standard linear adjustment of weaning weight to an age-constant basis for beef calves. J Anim Sci 70:1333-1341.

Schmitz F, Everett RW and Quaas RL (1991) Herd-year-season clustering. J Anim Sci 74:629-636.

Sivarajasingam S (1993) Comparison of alternative methods of handling contemporary group effects in animal model prediction. J Anim Breed Genet 110:401-411.

Teixeira RA and Albuquerque LG (2003) Enviromental effects on preweaning daily gain in Angus, Hereford, Nellore and Angus x Nellore and Hereford x Nellore crosses. Rev Bras Zootec 32:887-890.

Toral FLB, Alencar MM and Freitas AR (2007) Frequentist and bayesian approachs for genetic evaluation of Canchim beef cattle for growth traits. Rev Bras Zootec 36:43-53.

Torres-Júnior RAA and Toral FLB (2006) Alternative methods for the adjustment of weaning weights of beef cattle. In: $8^{\text {th }}$ World Congress on Genetics Applied to Livestock Production, Belo Horizonte.

Van Bebber J, Reinsch N, Junge W and Kalm E (1997) Accounting for herd, year and season effects in genetic evaluation of dairy cattle: A review. Livestock Prod Sci 51:191-203.

Van Vleck LD (1987) Contemporary groups for genetic evaluations. J Dairy Sci 70:2456-2464.

Villalba D, Casasús I, Sanz A, Estany J and Revilla R (2000) Preweaning growth curves in Brown Swiss and Pirenaica calves with emphasis on individual variability. J Anim Sci 78:1132-1140.

\section{Internet Resources}

Reyes A, Elzo MA, Roso VM, Fries LA and Carvalheiro R (2006) Efeitos não genéticos na composição dos grupos contemporâneos para o ganho de peso do nascimento a desmama de uma população multirracial Nelore $x$ Hereford. $43^{a}$ Reunião Anual da Sociedade Brasileira de Zootecnia, João Pessoa, PB, Brazil. Available at http://www.animal.ufl.edu/ elzo/Publications/Proceedings/2006/Sociedad $\% 20$ Brazileira\%20de\%20Zootecnia/Reyes\%20et\%20al._SBZ4 3_July-24-27-2006_Trabalho_HOMEPAGE.pdf.

\section{Associate Editor: Alexandre Rodrigues Caetano}

License information: This is an open-access article distributed under the terms of the Creative Commons Attribution License, which permits unrestricted use, distribution, and reproduction in any medium, provided the original work is properly cited.

Errata: Due an error, Table 3 in Ahead of Print version was replaced by Table 3 in this article. 